UDC 316.4

LBC 60.54

\title{
FACTORS AFFECTING THE SOCIAL AND CULTURAL ADAPTATION OF MIGRANTS FROM CENTRAL ASIA IN THE URAL MEGALOPOLIS
}

\author{
Elena V. Grunt \\ Ural Federal University named after the first President of Russia B.N. Yeltsin, \\ Yekaterinburg, Russian Federation
}

\begin{abstract}
The article presents the results of a sociological study conducted in October-December 2018 in Ekaterinburg. The subject of the study is the factors influencing the social and cultural adaptation of migrants from Central Asia in the Ural megalopolis. The sociological study was conducted using quantitative and qualitative strategies - the method of questionnaire survey $(n=400)$ and the method of in-depth interview $(n=10)$. The study revealed a new trend in the migrant environment of the Ural metropolis - the formation of ethnic establishment within the migrant community of the same nationality, which has a relatively high level of income, with a high probability of planning to stay in Russia and obtain citizenship.

The author concludes about a new phenomenon in migrant communities - the interaction of migrants with their compatriots left in the country of origin through a social network. Social networks (Vkontakte, Facebook, etc.) are now beginning to replace Diaspora in solving the problems that arise in migrants community in their host culture, especially at the initial stage of their social and cultural adaptation, which indicates the weakening of Diaspora relations of migrants. Every third respondent pointed to this factor. At the same time, the interaction of migrants with their compatriots through the social network, solving problems through social networks, conversation and communication in the network in their native language hinder the social and cultural adaptation of the migrant in the host culture.

The study finds out that for young people who came to the Urals from Central Asia it is more difficult to adapt to Russian culture. This is stipulated by the fact that the older generation migrants were socialized in the Soviet Union, learning Russian language, Russian culture, etc. Besides, the older generation does not see a significant difference between the two cultures. In this regard, it is easier for them to undergo social and cultural adaptation in Russia compared to young people. At the same time, the majority of migrants are young and middle-aged people.

The study reveals the leading external (education; cultural environment of the host community; age of the migrant; presence / absence of citizenship, etc.) and internal (interest in Russian culture, motivation to move to Russia) factors that ambiguously affect the social and cultural adaptation of migrants from Central Asia in the Ural metropolis.
\end{abstract}

Key words: migrants, Central Asia, Ural megalopolis, social and cultural adaptation, external and internal factors.

УДК 316.4

ББК 60.54

\section{ФАКТОРЫ, ВЛИЯЮЩИЕ НА СОЦИОКУЛЬТУРНУЮ АДАПТАЦИЮ МИГРАНТОВ ИЗ СРЕДНЕЙ АЗИИ В УРАЛЬСКОМ МЕГАПОЛИСЕ}

\author{
Елена Викторовна Грунт
}

\author{
Уральский федеральный университет им. первого Президента РФ Б.Н. Ельцина, \\ г. Екатеринбург, Российская Федерация
}

Аннотация. В статье представлены результаты социологического исследования, проведенного в октябре-декабре 2018 г. в г. Екатеринбурге. Предмет исследования - факторы, влияющие на социокультурную адаптацию мигрантов из Средней Азии в уральском мегаполисе. Социологическое исследование проведено с использованием количественной и качественной стратегии - метода анкетного опроса $(\mathrm{n}=400)$ и метода 
глубинного интервью $(\mathrm{n}=10)$. Исследование выявило новый тренд в мигрантской среде уральского мегаполиса - формирование этнической элиты внутри мигрантского сообщества той же национальности, которая имеет относительно высокий уровень дохода, с высокой вероятностью планирующая остаться в России и получить гражданство.

В статье делается вывод о новом явлении в мигрантских сообществах - взаимодействии мигрантов со своими соотечественниками, оставшимися в стране исхода, посредством социальной сети. Социальные сети (ВКонтакте, Facebook и др.) сегодня начинают заменять диаспоры в решении проблем, возникающих у мигрантов в принимающей их культуре, особенно на начальном этапе их социокультурной адаптации. Вместе с тем взаимодействие мигрантов со своими соотечественниками посредством социальной сети, решение проблем через социальные сети, разговор и общение в сети на родном языке препятствуют социокультурной адаптации мигранта в принимающей его культуре.

Исследование зафиксировало: молодежь, приехавшая на Урал из стран Средней Азии, более сложно адаптируется к российской культуре. Это связано с тем, что старшее поколение мигрантов проходило социализацию в СССР, обучаясь русскому языку, элементам русской культуры и проч. Кроме того, оно не видит существенной разницы двух культур. В этом плане им легче пройти социокультурную адаптацию в России по сравнению с молодежью. Вместе с тем большая часть мигрантов - люди молодежного и среднего возраста.

Исследование выявило ведущие внешние (образование; культурная среда принимающего сообщества; возраст мигранта; наличие / отсутствие гражданства и др.) и внутренние (интерес к русской культуре, мотивация переезда в Россию) факторы, неоднозначно влияющие на социокультурную адаптацию мигрантов из Средней Азии в уральском мегаполисе.

Ключевые слова: мигранты, Средняя Азия, уральский мегаполис, социокультурная адаптация, внешние и внутренние факторы.

\section{Введение в исследовательскую проблему}

Современные процессы, в том числе и миграционные, происходят в условиях глобализации, характеризуются значительными преобразованиями в экономике, политике, социальной сфере, культуре и т. д. Глобализация, с одной стороны, дала возможность расширения и стирания межнациональных границ, социокультурного пространства, мобильности и миграции людей, а с другой - создала серьезные проблемы, связанные с утратой идентичности народов, их культурной самобытности. В этих условиях наблюдается большая миграционная подвижность населения разных стран. Процессы размывания культурных и национальных границ государств (создание Евросоюза в Европе, СНГ на постсоветском пространстве), рост уровня миграции из мусульманских стран в Европе, из новых союзных среднеазиатских государств - бывших союзных республик в России и проч. оказывают большое влияние не только на процессы, происходящие в принимающем обществе, но и на процессы социокультурной адаптации мигрантов. Неспособность людей и государств решать проблемы, связанные с социокультурным разнообразием, миграционными потоками, приво- дит к кризису социокультурной адаптации личности. В этом плане социокультурная адаптация становится важной повседневной проблемой не только для людей, адаптирующихся к новой культурной среде, но и для принимающей их культуры.

Сегодня Уральский регион стал одним из ведущих, куда приезжают мигранты из Средней Азии. В настоящий момент проблема пребывания мигрантов из Средней Азии в уральских мегаполисах является очень актуальной, общественно и политически значимой. Мигранты из азиатских стран являются не просто демографическим резервом Урала, но и важным его трудовым потенциалом, важной составляющей современной экономической системы, поэтому проблема их социокультурной адаптации к российской культуре становится актуальной и имеет общегосударственный характер.

В этих условиях проблема миграции является одной из центральных в европейском [Bokek-Cohen, Lissitsa 2014; Dieterich-Hartwell, Koch 2017; Düvell, Vogel 2006; Flake 2013; Giuliani, Olivari, Alfieri 2017; Putnam 2007; Rebhun 2014] и российском [Бондырева, Колесов 2004; Брусина 2008; Зайончковская, Ноздрина 2008; Бородкина, Соколова, Тавровский (ред.) 2017; Мукомель 2005; Новоселова 2014; 
Рыбаковский 2003; Татарко 2009; Юдина 2002] научном дискурсе.

Проблемы социокультурной адаптации рассматривались в работах Т.Г. Стефаненко [Стефаненко 1996], исследователем обозначена его специфика. О. Брусина [Брусина 2008], Л. Дробижева [Дробижева 2003, 23] анализируют проблемы, возникающие у адаптантов в процессе их социокультурной адаптации. Н.В. Киммель, Е.В. Грунт провели исследование культурной идентичности и процесса адаптации русскоязычных эмигрантов на о. Бали и в Турции [Грунт, Киммель 2014]. С. Гулиани с коллегами занимаются вопросами социокультурной адаптации мусульманских юношей и девушек в Германии [Giuliani, Olivari, Alfieri 2017; Georgiadou, Morawa, Erim 2017]; У. Ребхун занимается проблемами русскоязычных мигрантов в Израиле [Rebhun 2014] и т. д. Между тем анализ научной литературы показывает, что существует недостаточно социологических исследований, посвященных анализу факторов, влияющих на социокультурную адаптацию мигрантов.

Исследователи рассматривают различные факторы, влияющие на разные аспекты социокультурной адаптации мигрантов. Так, У. Эль-Эод, Ф. Петерман и др. анализируют умение управления эмоциями, межкультурную компетентность и умение постановки / достижения целей мигрантами в новой среде как важные факторы, влияющие на их социокультурную адаптацию [El-Awad et al. 2017]. Они полагают, что межкультурная компетентность способствует адаптации мигрантов к новым условиям жизни, давая знания о различиях культуры, традиций, ценностей и норм. Умение контролировать и регулировать эмоции позволяет человеку позитивно переоценивать культурные различия, что способствует психологической адаптации мигрантов. Постановка целей и их достижение обеспечивают личности успешную адаптацию к новой культурной среде [Castles, Miller 1996]. Мы согласны с исследователями, что эти факторы важны при социокультурной адаптации мигрантов. Однако на практике большая часть последних не обладает межкультурными компетенциями, да и не все они могут ставить цели в новой для них социокультурной среде.
Р. Дейтрич-Хартуелл и С. Кох рассматривали факторы тоски по Родине и отсутствие возможности вернуться на Родину у мигрантов как одни из важных факторов, влияющих на их социокультурную адаптацию. Исследователи делают вывод о том, что эти факторы могут вызвать чувства ностальгии, что в итоге приводит к дезадаптации [Dieterich-Hartwell, Koch 2017].

Д. Родес изучала влияние религиозного фактора на социокультурную адаптацию мигрантов, в частности, влияние буддийской религиозной культуры на данный процесс для вьетнамских мигрантов в США. Автор отмечает, что буддийские лидеры участвуют в сохранении и поддержании вьетнамской культуры и формировании вьетнамского сообщества в южных штатах США. Мигрант при этом, ориентируясь на американскую культуру, должен сохранять культуру страны исхода, создавая свое сообщество, вносить существенный вклад в принимающую культуру [Rhodes 2016].

О. Лоебер и другие изучали фактор репродуктивного поведения мигрантов, влияющий на социокультурную адаптацию турецких мигрантов в Нидерландах. По мнению О. Лоебеpa, турецкие женщины второго поколения мигрантов быстрее адаптируются к новой культуре, чем их коллеги-мужчины [Loeber 2008].

Е. Морава и Я. Ерим считают, что культурные ориентации и ценности мигрантов важные факторы их социокультурной адаптации. Изучив культурные ориентации турецких мигрантов в Германии, исследователи делают вывод о том, что ориентации мигрантов на культуру Германии положительно влияют на их социокультурную адаптацию [Morawa, Erim 2014, 9514]. Однако, как показало их исследование, лишь незначительная часть мигрантов ориентирована на культуру Германии.

Н.В. Киммель, изучая проблемы культурной идентичности русскоязычных мигрантов в Турции и Индонезии, выделяет следующие факторы, влияющие на нее: особенности культуры родной страны, референтную группу, культурную дистанцию, условия культуры пребывания, семью, диаспору, мотивы выезда в другую страну, интерес к освоению новой культуры, личностные качества индивида, особенности культуры страны пребывания, 
культуру конкретной диаспоры; религию; личный опыт мигранта пребывания в другой стране [Киммель 2011, 126].

Рассмотрев различные подходы к анализу факторов, имеющиеся в научной литературе, можно сделать вывод о том, что на процесс социокультурной адаптации мигрантов оказывают влияние внешние и внутренние факторы. Их анализу посвящено наше исследование.

\section{Методы и методология исследования}

Цель исследования - изучить факторы, влияющие на социокультурную адаптацию мигрантов из Средней Азии в уральском мегаполисе.

Социологическое исследование проведено в октябре-декабре 2018 г. в г. Екатеринбурге с использованием количественной и качественной стратегии - метода анкетного опpoca $(\mathrm{n}=400)$ и метода глубинного интервью $(\mathrm{n}=10)$. Выборка - стихийная обусловлена тем, что трудовые мигранты представляют собой закрытую социальную группу, которая тяжело идет на контакт. Существует ряд причин (трудности с языком, высокая занятость, проблемы с легальным нахождением или деятельностью на территории РФ и т. д.), которые затрудняют их изучение. Из опрошенных мигрантов $-63,4 \%$ мужчин и $36,6 \%$ женщин, что вполне соответствует пропорциональному гендерному соотношению мигрантов, проживающих в уральском мегаполисе. В ходе исследования было проведено 10 экспертных интервью с мигрантами, прожившими в российской культуре более десяти лет и прошедшими социокультурную адаптацию.

\section{Процедура исследования}

Качественное исследование: глубинное интервью. Проведено разведывательное исследование с участниками глубинного интервью (десять 45-минутных глубинных интервью). Участники - мигранты, которые прожили в г. Екатеринбурге более десяти лет и прошли период социокультурной адаптации. Респондентам были заданы вопросы, имеющие отношение к цели исследования, чтобы определить основные проблемы и факторы социокультурной адаптации.
Количественное исследование: анкетный опрос. Количественная стратегия была проведена с использованием анкетного опроса. Анкета сформулирована в результате проведения глубинных интервью с участниками, описанными выше. Анкета для мигрантов состояла из 44 вопросов.

Феномен «социокультурная адаптация» мигрантов был рассмотрен с позиций структурно-функционального и аксиологического подходов, что позволило сделать вывод о том, что социокультурная адаптация представляет собой важный полифункциональный, многогранный социокультурный процесс.

Рамки статьи не позволяют рассмотреть все имеющиеся подходы к понятию «социокультурная адаптация». В исследовании используется рабочее определение этого термина, под которым понимается особая форма взаимодействия мигранта с принимающей культурой по освоению новых ценностей, традиций и норм культуры, создающая личности условия для эффективного вхождения в новую социокультурную среду и освоения различных форм социокультурной деятельности.

\section{Результаты исследования и дискуссия}

Исследование зафиксировало, что 40,7 \% мигрантов прибыло из Кыргызстана, по 19,3 \% - из Узбекистана и Таджикистана. $11,3 \%$ респондентов отметило, что их Родиной является Казахстан. 6,0 \% мигрантов прибыло в Россию из Туркмении. 3,3 \% респондентов прибыло на Урал из других регионов.

Наше исследование подтвердило результаты исследования московских социологов: в последнее время большинство мигрантов прибывает в Россию, в том числе и на Урал, из Кыргызстана [Батенева 2013; Варшавер и др. web], что свидетельствует о новом миграционном российском тренде.

Анализ результатов исследования показал, что в составе опрошенных преобладают мигранты-мужчины - 63,4 \%, соответственно представители женского пола составляют $36,6 \%$.

Исследование показало, что мигранты имеют достаточно высокий уровень образования. Таким образом, вопреки сложившемуся общественному мнению россиян о низком 
образовательном уровне мигрантов из Средней Азии, в целом уровень образования респондентов достаточно высок, что, на наш взгляд, помогает им, при желании, проще адаптироваться к новым социокультурным условиям проживания и найти работу.

Относительно социального статуса мигрантов исследование показало, что мигранты - это в основном работающее население, за исключением женщин, приехавших за мужьями и воспитывающих детей $(25,0 \%)$. Ocновными сферами занятости являются транспорт, строительство, торговля. 8,3 \% мигрантов имеют свой бизнес.

Охарактеризовав респондентов по их социально-демографическим характеристикам, перейдем к рассмотрению основных внешних факторов, оказывающих влияние на социокультурную адаптацию мигрантов из стран Средней Азии.

Возраст мигранта, на наш взгляд, является одним из главных факторов, влияющих на его социокультурную адаптацию. Как отмечают исследователи [Абдуллаев 2008; Киммель 2011, 123; Barrett 1996], лучше всего адаптируются к новой культуре дети, труднее всего - люди пожилого возраста, поскольку им сложнее принять нормы, ценности, язык, традиции чужой для них культуры. Однако наше исследование показало противоположную ситуацию. Молодежь, приехавшая на Урал из стран Средней Азии, более сложно адаптируется к российской культуре. Это связано с тем, что старшее поколение мигрантов проходило социализацию в СССР, обучаясь русскому языку, элементам русской культуры и проч. В этом плане им легче пройти социокультурную адаптацию в России по сравнению с молодежью. Вместе с тем, как показало наше исследование, большая часть мигрантов - люди молодежного и среднего возраста.

Следующий важный фактор - полученное мигрантами образование и система образования разных стран. Образовательный уровень мигрантов часто не соответствует общепринятым стандартам качества образования. Это связано, прежде всего, с низким экономическим уровнем стран Средней Азии. Также нестабильность экономики в этих странах приводит к раннему прекращению обучения, в пользу начала трудовой деятельности.
Это показало наше исследование. Несмотря на достаточно высокий образовательный уровень мигрантов, большинство из них работает не по специальности, что неблагоприятно сказывается на их социокультурной адаптации: "По специальности я инженер, в России работаю в такси... Нет работы по специальности ни в России, ни в Киргизии..» (мужчина, таксист, 51 год, проживает в России 10 лет). Тем не менее уровень образования может серьезно влиять на успешность адаптации, особенно на первых этапах. У мигранта, знающего русскую культуру и русский язык и окончившего хотя бы среднее специальное заведение, например, техникум или колледж (каждый третий респондент, участвующий в нашем исследовании, окончил его), больше шансов по сравнению с человеком, не имеющим образования, найти подходящую себе должность или трудоустроиться. При этом у него реже возникают материальные и финансовые трудности, которые являются одними из основных сложностей в самом начале адаптационного периода.

Как показало наше исследование, такие факторы, как наличие гражданства и легальность положения мигранта в России, влияют на социокультурную адаптацию. Достаточно большая часть мигрантов находится на Урале нелегально. С одной стороны, это связано со сложностью оформления документов, с другой - с недобросовестностью и незаинтересованностью части работодателей в оказании мигрантам помощи в легализации. Нелегальное положение мигрантов в принимающей культуре приводит к ряду проблем: сложности с трудоустройством (30,0\%), социальноправовой незащищенности перед работодателем $(35,0 \%)$, столкновению с полицией $(23,0 \%)$, проблемам с поисками жилья $(28,0 \%)$. Нелегальные мигранты, находясь на территории принимающей их культуры, часто нарушают законодательство. Все это приводит к дезадаптации в новой для них культуре, к попытке быть «незамеченными»: «Среди нас много нелегально проживающих в Екатеринбурге. Многие из них хотят остаться здесь жить... У них нет никаких прав. Работодатели им не помогают. Они просто выљсивают...» (мужчина, 45 лет, проживает в России 12 лет). 
Легальные мигранты, а также получившие гражданство имеют более высокий социальный статус, им легче трудоустроиться или найти жилье. Можно выделить этническую элиту внутри мигрантского сообщества - представителей этой же национальности, которые имеют относительно высокий уровень дохода и социальный статус. Исследование показало, что представители мигрантской этнической элиты чаще других мигрантов планируют остаться в уральском мегаполисе в качестве граждан. На этот факт указал каждый пятый респондент. Они могут иметь в России свой небольшой бизнес: от «точки на рынке», «кафе», «парикмахерской» и т. д., сами выступая в роли работодателя (8,3 \%). Исследование показало, что такие мигранты живут в большинстве своем полными семьями и у них не возникает проблем с обязанностью обеспечивать родственников, оставшихся в стране исхода $(6,5$ \%). При этом следует учитывать, что все перечисленное, хотя и оказывает сильное положительное влияние, но не дает полной гарантии социокультурной адаптации и стратегии интеграции в российскую культуру, так как наличие этих возможностей (жизнь с семьей и наличие собственности, бизнеса) может, напротив, лишить задачи мигранта интегрироваться в новую культуру.

Наличие гражданства, равно как и перспектива его получения, также является важным фактором. Те мигранты, которые получили его либо имеют такую возможность, чаще остаются на Урале с положительной ориентацией на социокультурную адаптацию. На это указало 45,0 \% респондентов.

Как отмечает Н.В. Киммель, на формирование социокультурной адаптации мигранта влияет фактор культурной дистанции. Под культурной дистанцией понимается «степень различий между родной культурой и той, к которой адаптируется личность, а также степень близости или отчуждения личности от данной культуры... Для ее обозначения в культуре выработаны различные средства. К ним относятся язык, символы, знаки, ценности, действия. Здесь важно отметить тот факт, что на процесс формирования новой культурной идентичности влияет даже не сама культурная дистанция, а представление человека о ней и ощущение ее, которые зависят от многих факторов: наличия или отсутствие конфликтов как в родной, так и в чужой для него культуре; знание чужого языка и культуры и др.» [Киммель 2011, 126].

Рассмотрим несколько индикаторов культурной дистанции: объективные - язык; субъективные - отношение к русской культуре и ее восприятие. Проблемы с русским языком ограничивают возможности мигранта в коммуникации и установлении контактов с местным населением, что приводит к осложнениям в социокультурной адаптации. Если мигрант достаточно хорошо владеет русским языком, то успешность адаптации, как правило, зависит от его желания сделать это. Многие исследования показывают, что хуже всего владеют языком те, кто родился после распада СССР, - молодые люди до 35 лет [Батенева 2013]. При этом в любом случае подавляющее большинство считает, что их дети должны изучать русский язык $(65,5 \%)$. Это зависит от региона исхода. Мигранты, которые приехали на Урал из сельских регионов Средней Азии, зачастую имеют низкий уровень образования и квалификации, плохо / coвсем не владеют русским языком, не знают русской культуры, что усложняет их социокультурную адаптацию. Кроме того, мигранты из Киргизии лучше владеют русским языком, чем представители других среднеазиатских стран, так как последний в их стране второй национальный. Исследование зафиксировало, что большинство мигрантов (около $70,0 \%$ ) общается в повседневной жизни на родном языке, у трети респондентов есть трудности с общением в новой культурной среде (в этом плане язык является важным фактором, препятствующим социокультурной адаптации мигрантов).

Что касается интереса к русской культуре со стороны мигрантов, то чаще всего наблюдается его отсутствие либо пассивность проявления. При этом, находясь в данной культурной среде, мигранты из Средней Азии могут не проявлять никакого интереса, но не возражают насчет того, чтобы взаимодействовать с людьми, находящимися в данном социокультурном пространстве. Серьезное негативное влияние оказывает сепаративный подход, положительное - отождествление родной для мигранта культуры с русской. Как 
правило, более старшее поколение мигрантов не видит особой разницы двух культур, так как оно проходило социализацию в СССР и училось по образовательным программам, принятым в Советском Союзе.

Исследование показало, что у части мигрантов (около 30,0 \%) присутствует интерес к изучению русского языка, а к русским традициям и обычаям варьируется от простой информированности до непосредственного исполнения. Последнее способствует более успешной социокультурной адаптации.

Важным объективным фактором, влияющим на социокультурную адаптацию мигрантов, являются особенности культуры страны исхода. Анализ причин переезда мигрантов в Россию показал, что они способствовали осознанному (а не вынужденному, например, вследствие депортации) желанию переехать в Россию. При этом желание вернуться домой для $86,0 \%$ респондентов говорит о том, что они не готовы адаптироваться к новой для них культуре. В связи с этим, на наш взгляд, данный фактор может как способствовать социокультурной адаптации тех мигрантов, которые желают остаться в России, так и препятствовать этому процессу - для желающих вернуться домой.

Религия - один из основных факторов социокультурной адаптации мигранта. Мигранты из стран Средней Азии, как правило, мусульмане и, оказываясь в чужом обществе, начитают искать поддержку в своей конфессии. Почти все они достаточно религиозны (до $80,0 \%$ ), и многие строго или частично придерживаются своих традиций $(66,7 \%)$, однако это не является серьезным барьером их социокультурной интеграции. Исследование показало, что значительная часть мигрантов положительно относится к русским обычаям и праздникам, в том числе и христианским (Пасха, Рождество), вполне успешно придавая им не столько религиозное, сколько культурное значение, что не вступает в конфликт с их приверженностью своим традициям и религии. Кроме того, российский народ оказывается гораздо менее религиозным и достаточно толерантным к другим религиям.

Семья является неоднозначным фактором, влияющим на социокультурную адаптацию мигрантов. Большинство мигрантов (око- ло 70,0 \%) приезжают на Урал одни в поисках работы, при этом оставляя свою семью в стране исхода. Часть из них через некоторое время (после устройства на работу) перевозит на Урал членов своей семьи. В процессе исследования выяснено, что $46,7 \%$ женаты или замужем, а $37,6 \%$ не состоят в браке. Около $17,0 \%$ респондентов не смогли определить свое семейное положение, так как официально не состоят в браке. Проблема заключается в том, что различное семейное положение может как положительно, так и отрицательно влиять на успешность социокультурной адаптации мигрантов. Предполагается, что потенциал к адаптации и вовлеченность в новую социокультурную среду выше в том случае, если мигранты приезжают с семьями. Респонденты говорят о том, что они приезжают в Россию ради благополучия своих семей и несовершеннолетних детей: «Большинство из нас приезжает сюда без семьи... Зарабатывая, мы пересылаем деньги на Родину, тем самым поддерживаем финансово детей и жен» (мужчина, 45 лет, проживает в России 12 лет). В связи с этим у респондентов, приехавших на Урал заработать деньги и вернуться домой, отсутствует потребность в социокультурной адаптации или же достаточно четко выражена стратегия пассивной социокультурной адаптации.

Следующий важный фактор - диаспоpa. Однако, как показало наше исследование, лишь 14,8 \% респондентов обращаются к ней за помощью. При этом даже непостоянное взаимодействие мигрантов со своими соотечественниками имеет значение при помощи в решении их проблем. Это справедливо по отношению не только к диаспоре в целом, но и к друзьям, знакомым и родственникам мигрантов. За помощью к ним они обращаются чаще всего и совместно с ними проживают на территории уральского мегаполиса. Если учитывать, что это именно те знакомые и родственники, которые приехали в Россию ранее и уже сами имеют адаптационный опыт, то с их стороны действительно может быть оказана помощь в освоении новой культурной среды, и такое взаимодействие будет положительным моментом. Но всегда стоит учитывать, что при отсутствии личной мотивации, это может иметь обратный характер. 
Иначе говоря, в уральском мегаполисе существуют мигрантские социальные сети, которые, создавая особые социальные отношения доверия, сочувствия, приобретения социального капитала и проч., - помогают мигранту преодолеть чувство тоски по Родине, отчужденности, решать возникающие проблемы, создавать сеть личных знакомств и прочее. Эти сети являются неким «социальным буфером» при вхождении мигранта в новое социокультурное сообщество. В то же время некоторые исследователи считают, что мигранты, поддерживающие межличностные отношения преимущественно или исключительно в кругу своих земляков, оказываются слабо мотивироваными к адаптационной деятельности [Варшавер и др. web].

Существуют также факторы, выступающие со стороны самой принимающей культуры, влияющие на социокультурную адаптацию мигрантов. Как отмечает Е.В. Батенева, все еще существует проблема отношения местного населения к приезжим, из-за чего мигранты могут чувствовать себя не до конца своими в данном обществе, не важно, сколько они в нем прожили [Батенева 2013]. На этот фактор указало 20,0 \% респондентов. Те же отмеченные проблемы с жильем могут часто возникать из-за предвзятого отношения арендаторов к представителям Средней Азии.

Российская миграционная политика как показатель культуры принимающего сообщества также выступает значимым фактором. Законодательство несколько ужесточило легальность пребывания мигрантов из Средней Азии в России, но вместе с тем происходит направленность на создание некоторой мотивации мигрантов к интегрированию. Однако сегодня для получения патента, сертификата для временного проживания и разрешения на работу они должны сдать обязательные экзамены по трем дисциплинам - русский язык, история России и правоведение, что при желании мигранта способствует его более успешной социокультурной адаптации.

Это можно рассматривать в положительном ключе, так как идет направленность на стимулирование владением мигранта определенным уровнем языка, а также на формирование представлений о российской культуре. При этом следует учитывать, что российская политика по отношению к трудовым мигран- там не всегда имеет возможность удовлетворить их потребности в плане трудовых, правовых и социальных гарантий. На этот фактор указали все наши информанты.

СМИ - фактор, негативно влияющий на социокультурную адаптацию мигрантов из Средней Азии: «Российские СМИ очень некрасиво говорят о нас. На всех каналах говорится, что мы везде виноваты: алкоголь, наркотики, криминал, террор. Все это плохо на нас влияет...» (мужчина, таксист, киргиз, 51 год).

Исследование выявило роль социальных сетей (ВКонтакте, Facebook) как важного фактора, влияющего на социокультурную адаптацию мигрантов. В отсутствии друзей в принимающей культуре они обращаются за помощью к друзьям, членам семьи, оставшимся в стране исхода. На этот фактор указал каждый третий мигрант. Взаимодействие со своими соотечественниками посредством социальной сети, решение с их помощью своих проблем, общение при этом на родном языке препятствует социокультурной адаптации мигранта в принимающей его культуре.

Важными субъективными факторами являются мотивы переезда в государство с чужой культурой и те цели, которые преследует мигрант. Эти последние, а также изначальные установки по отношению к российскому обществу и культуре, влияют на дальнейшее поведение в социокультурной адаптации. Трудовые мигранты, приезжая только на заработки, имеют много возможностей успешно пройти процесс социокультурной адаптации, даже не имея изначально таких ориентиров. Наше исследование показало, что мигранты, у которых наблюдается твердое намерение вернуться в страну исхода, часто проявляют низкую интегрированность в российское общество. Те, кто планирует остаться или фактически остается, обладают большим адаптационным потенциалом и высокой интегрированностью в российское общество.

Что касается личного опыта мигрантов пребывания в другой культуре, то большинство (более $80,0 \%$ ) его не имеет, что негативно сказывается на их социокультурной адаптации. Как мы видим, на успешность социокультурной адаптации мигрантов влияют различные объективные и субъективны факторы. 


\section{Заключение}

Данные нашего исследования свидетельствуют о том, что в целом мигранты из Средней Азии - это разновозрастная группа (с преобладанием молодого поколения), различная по гендерному аспекту (с преобладанием мужчин), с достаточно высоким уровнем образования (полное среднее, среднее специальное и высшее) и материального обеспечения, достаточно разнородная по сфере занятости. Большая часть мигрантов $(65,0 \%)$ реализовала свои цели при переезде на Урал.

Большинство мигрантов не видят различий русской и их национальной культуры: чем старше мигрант, тем меньше различий культур он ощущает. 60,0 \% из них избрали интегративную стратегию социокультурной адаптации. Именно эти мигранты являются тем потенциалом, который даже при желании вернуться в страну исхода может остаться в принимающей культуре на постоянное место жительства. Мы полагаем, что необходима миграционная политика на областном уровне, направленная на работу с этими мигрантами в плане их успешной социокультурной адаптации в уральском мегаполисе.

Исследование выявило новый тренд в мигрантской среде уральского мегаполиса формирование некой этнической элиты внутри мигрантского сообщества той же национальности, которая имеет достаточно хорошее материальное и финансовое обеспечение, относительно высокую степень социокультурной адаптации и достаточно высокую степень вероятности остаться в России на постоянное место жительства.

Новым явлением в мигрантских сообществах является взаимодействие мигрантов со своими соотечественниками, оставшимися в стране исхода, посредством социальной сети. Именно социальные сети сегодня начинают заменять диаспоры в решении проблем, возникающих у мигрантов в принимающей их культуре, особенно на начальном этапе их социокультурной адаптации, что свидетельствует об ослаблении диаспоральных связей мигрантов.

Исследование выявило внешние и внутренние факторы, неоднозначно влияющие на социокультурную адаптацию мигрантов из Средней Азии в уральском мегаполисе. Веду- щие внешние факторы - образование, культурная среда принимающего сообщества, возраст мигранта, наличие / отсутствие гражданства и легальность положения, культурная дистанция, семья, СМИ. Религия не является фактором, существенно влияющим на социокультурную адаптацию мигрантов из Средней Азии.

Ведущие внутренние факторы, влияющие на социокультурную адаптацию мигрантов из Средней Азии, - мотивация переезда, интерес к русской культуре.

\section{СПИСОК ЛИТЕРАТУРЫ}

Абдуллаев 2008 - Абдуллаев Е.В. Трудовая миграция как феномен развивающегося общества // Трудовая миграция в Республике Узбекистан: социальные, правовые и гендерные аспекты: сб. ст. Ташкент: [б. и.]. 2008. С. 12-23.

Батенева 2013 - Батенева Е.В. Культурная адаптация экономических мигрантов из стран Центральной Азии в столичном регионе: сущность и механизмы: дис. ... канд. культурол. наук. М.: МГУКиИ, 2013.

Бондырева, Колесов 2004 - Бондырева С.К., Колесов B.T. Миграция (сущность и явление). Воронеж: МПО МОДЭК, 2004.

Бородкина, Соколова, Тавровский (ред.) 2017 - Бородкина О.И., Соколова Н.В., Тавровский А.В. (ред.). Международная миграция в Санкт-Петербурге: социальная политика и общественное мнение: коллектив. моногр. СПб.: Скифияпринт, 2017.

Брусина 2008 - Брусина О.И. Мигранты из Средней Азии в России: этапы и причины приезда, социальные типы, организации диаспор // Вестник Евразии. 2008. № 2. С. 66-95.

Варшавер и др. web - Варшавер Е.А., Рочева А.Л., Кочкин Е.В., Кулдина Е.С. Киргизские мигранты в Москве: результаты количественного исследования интеграционных траекторий [Social Science Research Network] // http:// papers.ssrn.com/sol3/papers.cfm?abstract id $=2425312$.

Грунт, Киммель 2014 - Грунт Е.В., Киммель Н.В. Особенности русскоязычной диаспоры на о. Бали // Известия УРФУ. Серия 3, Общественные науки. 2014. № 4 (134). С. 193-200.

Дробижева 2003 - Дробижева Л.М. Социальные проблемы межнациональных отношений в постсоветской России. М.: Центр общечеловеч. ценностей, 2003.

Зайончковская, Ноздрина 2008 - Зайончковская Ж.А., Ноздрина Н.А. Миграционный опыт на- 
селения региональных центров России (напримере социологического опроса в 10 городах) // Проблемы прогнозирования. 2008. № 4. C. 98-112.

Киммель 2011 - Киммель Н.В. Особенности формирования культурной идентичности русскоязычной диаспоры в мусульманских странах: дис. ... канд. социол. наук. Екатеринбург: УрГУ, 2011.

Мукомель 2005 - Мукомель В.И. Миграционная политика России. Постсоветские контексты. М.: Ин-т социологии РАН, 2005.

Новоселова 2014 - Новоселова Е. Нофелет для мигранта // Российская газета. Федеральный выпуск. 2014. 18 авг. (№ 6457 (185)).

Рыбаковский 2003 - Рыбаковский Л.Л. Миграция населения (вопросы теории). М.: Ин-т соц.полит. иссл. РАН, 2003.

Стефаненко 1996 - Стефаненко Т.Г. Адаптация к новой культурной среде и пути ее оптимизации // Введение в практическую социальную психологию. М.: Смысл, 1996. С. 167-185.

Татарко 2009 - Татарко А.Н. Мигранты в Москве: угрозы истинные и мнимые // Миграционные процессы и проблемы адаптации. Пенза: ПГПУ им. В.Г. Белинского, 2009.

Юдина 2002 - Юдина Т.Н. О социологическом анализе миграционных процессов // Социологические исследования. 2002. № 10 . C. 102-109.

Barrett 1996 - Barrett M. English children's acquisition of a European identity // Changing European Identities: Social-Psychological Analyses of Social Change. Oxford: ButterworthHeinemann, 1996. P. 145-172.

Bokek-Cohen, Lissitsa 2014-Bokek-Cohen Y., Lissitsa $S$. The Impact of Social Netwowk on Spousal influence strategies during couple purches // Известия УРФУ. Серия 3, Общественные науки. 2014. С. 54-67.

Castles, Miller 1996 - Castles S., Miller M.J. The age of Migration: International Population Movements in the Modern World. L.: Macmillan, 1996.

Dieterich-Hartwell, Koch 2017 - Dieterich-Hartwell R., Koch S.C. Creative Arts Therapies as Temporary Home for Refugees: Insights from Literature and Practice // Behavioral Sciences 2017. № 7. P. 69-87.

Düvell, Vogel 2006 - Düvell F., Vogel D. Polish migrants: Tensions between sociological typologies and state categories // Triandafyllidou. A. (ed.) Contemporary Polish migration in Europe: Complex patterns of movement and settlement. Lewiston, N.Y.: Edwin Mellen Press. P. 267-289.
El-Awad et al. 2017 - El-Awad U., Fathi A., Petermann $F$, Reinelt $T$. Promoting Mental Health in Unaccompanied Refugee Minors: Recommendations for Primary Support Programs // Brain Sciences. 2017. Vol. 7, iss. 146. P. 246268. DOI:10.3390/brainsci7110146.

Flake 2013 - Flake R. Gender Differences in the Earnings Mobility of Migrants // Labour. 2013. Vol. 27, iss. 1. P. 58-79. DOI: 10.1111/j.14679914.2012.00557.x.

Georgiadou, Morawa, Erim 2017 - Georgiadou E., Morawa E., Erim Y. High Manifestations of Mental Distress in Arabic Asylum Seekers Accommodated in Collective Centers for Refugees in Germany // International Journal of Environment Research and Public Health. 2017. Vol. 14. P. 612-627. DOI:10.3390/ ijerph14060612.

Giuliani, Olivari, Alfieri 2017 - Giuliani C., Olivari M.G., Alfieri S. Being a "Good" Son and a "Good" Daughter: Voices of Muslim Immigrant Adolescents // Social Sciences. 2017. Vol. 6, iss. 142. P. 66-87. D O I : $10.3390 / \mathrm{s}$ o c s c i 6040142 .

Loeber 2008 - Loeber $O$. Sexual and reproductive health issues of Turkish immigrants in the Netherlands // The European Journal of Contraception \& Reproductive Health Care. 2008. Vol. 13, iss. 4. P. 330-338.

Morawa, Erim 2014-Morawa E., Erim Y. Acculturation and Depressive Symptoms among Turkish Immigrants in Germany // International Journal Environment Researches and Public Health. 2014. № 11 (9). P. 9503-9521. DOI:10.3390/ ijerph110909503.

Putnam 2007 - Putnam R. E Pluribus Unum: Diversity and community in the twenty-first century. The 2006 Johan Skytte Prize Lecture // Scandinavian Political Studies. № 30. P. 137-174. DOI:10.1111/ j.1467-9477.2007.00176.x.

Rebhun 2014 - Rebhun U. Immigrant Acculturation and Transnationalism: Israelis in the United States and Europe Compared // Journal for the Scientific Study of Religion. 2014. Vol. 53, iss. 3. P. 613-635. DOI: 10.1111/jssr.12135.

Rhodes 2016 - Rhodes D. The Dual Role a Buddhist Monk Played in the American South: The Balance between Heritage and Citizenship in the Refugee Community // Religions. 2016. Vol. 7, iss. 50. DOI:10.3390/rel7050050.

\section{REFERENCES}

Abdullaev E.V., 2008. Labour migration as a phenomenon of a developing society. 
Trudovaya migracziya $v$ Respublike Uzbekistan: sb. st. Tashkent, pp. 12-23.

Bateneva E.V., 2013. Cultural adaptation of migrants from Central Asia in central region: state and mechanisns: Phd thesis on culturology. Moscow, MSUKA.

Bondyreva S.K., Kolesov T.V., 2004. Migration: essence and phenomenon. Moscow, Izd-vo Mosk. psikhol.-socz. in-ta; Voronezh, Izd-vo MPOMODE`K, 2004.

Borodkina O. I., Sokolova N.V, Tavrovsky A.V. (ed.), 2017. International Migration in St. Petersburg: Social Policy and Public Opinion: A Collective Monograph. Saint Petersburg, Skifiya-print.

Brusina O.I., 2008. Migrants from Central Asia in Russia: stages and reasons for arrival, social types, organizations of diasporas. Vestnik Evrazii, no. 2, pp. 66-95.

Varshaver E.A., Rocheva A.L., Kochkin E.V, Kuldina E.S. Kyrgyz migrants in Moscow: results of a quantitative study of integration trajectories. Social Science Research Network. URL: http:// papers.ssrn.com/sol3/papers.cfm? abstract_id $=2425312$ (accessed 20 December 2018).

Grunt Ye.V., Kimmel N.V., 2014. Charactres of Russianspeaking diaspora in Bali. Izvestiye URFU. Seriya 3, Obshchestvennyye nauki, no. 4, iss. 134, pp. 193-200.

Drobizheva L.M., 2003. Social problems of interethnic relations in post-Soviet Russia. Moscow, Center of universal values.

Zajonchkovskaya Zh.A., Nozdrina N.A., 2008. Migration experience of Russian regional centers population (the example of a sociological survey in 10 cities). Problemy prognozirovaniya, no. 4 , pp. $98-112$.

Kimmel N.V., 2011. Features of the cultural identity formation of the Russian-speaking diaspora in Muslim countries. Yekaterinburg, UrGU.

Mukomel V.I., 2005. Migration policy of Russia. PostSoviet contexts. Moscow, Institute of sociology RAS.

Novoselova E., 2014. Nofelet for the migrant. Rossijskaya gazeta. Federal'ny'j vy'pusk, 18 August (no. 6457 (185)).

Rybakovskiy L.L., 2003. Migration of the population (theory questions). Moscow, Institute of social and political studies RAS.

Stefanenko T.G., 1996. Adaptation to the new cultural environment and ways of its optimization. Vvedenie $v$ prakticheskuyu soczial'nuyu psikhologiyu. Moscow, Smysl, pp. 167-185.

Tatarko A.N., 2009. Migrants in Moscow: true and imaginary threats. Migratsionnyi protsesyi I adaptatsionnyi pronlemyi. Penza, PGPU im. V.G. Belinskogo, pp. 73-97.

Yudina T.N., 2002. On the sociological analysis of migration processes. Socziologicheskie issledovaniya, no. 10, pp. 102-109.

Barrett M., 1996. English children's acquisition of a European identity. Changing European Identities: Social-Psychological Analyses of Social Change. Oxford Pergamon Press, pp. 145-172.

Bokek-Cohen Y., Lissitsa S., 2014. The Impact of Social Netwowk on Spousal influence strategies during couple purches. Izvestiya URFU. Seriya 3, Obshhestvennye nauki, no. 4 (134), pp. 201-217.

Castles S., Miller M.J., 1996. The age of Migration: International Population Movements in the Modern World. London, Macmillan, UK.

Dieterich-Hartwell R., Koch S.C., 2017. Creative Arts Therapies as Temporary Home for Refugees: Insights from Literature and Practice. Behaviral Sciences, no. 7, pp. 69-87.

Düvell F., Vogel, D., 2006. Polish migrants: Tensions between sociological typologies and state categories. Contemporary Polish migration in Europe: Complex patterns of movement and settlement. Lewiston, New York, Edwin Mellen Press, pp. 267-289.

El-Awad U., Fathi A., Petermann F., Reinelt T., 2017. Promoting Mental Health in Unaccompanied Refugee Minors: Recommendations for Primary Support Programs. Brain Sciences, vol. 7, iss. 146, pp. 246-268. DOI:10.3390/ brainsci7110146.

Flake R. 2013. Gender Differences in the Earnings Mobility of Migrants. Labour, vol. 27, iss. 1, pp. 58-79. DOI: 10.1111/j.1467-9914.2012.00557.x.

Georgiadou E., Morawa E., Erim Y., 2017. High Manifestations of Mental Distress in Arabic Asylum Seekers Accommodated in Collective Centers for Refugees in Germany. International Journal Environment Researches and Public Health, vol. 14, pp. 612-627. DOI:10.3390/ ijerph14060612.

Giuliani C., Olivari M.G., Alfieri S., 2017. Being a "Good" Son and a "Good" Daughter: Voices of Muslim Immigrant Adolescents. Social Sciences, vol. 6, iss.142, pp. 66-87. DOI:10.3390/ socsci6040142.

Loeber O., 2008. Sexual and reproductive health issues of Turkish immigrants in the Netherlands. The European Journal of Contraception \& Reproductive Health Care, vol. 13, iss. 4, pp. 330-338.

Morawa E., Erim Y., 2014. Acculturation and Depressive Symptoms among Turkish Immigrants in 
E.B. Грунт. Факторы, влияющие на социокультурную адаптацию мигрантов из Средней Азии

Germany. International Journal of Environment Researches and Public Health, vol. 11, pp. 9503-9521. DOI:10.3390/ ijerph110909503.

Putnam R., 2007. E Pluribus Unum: Diversity and community in the twenty-first century. The 2006 Johan Skytte Prize Lecture. Scandinavian Political Studies, no. 30, pp. 137-174. DOI:10.1111/j.1467-9477.2007.00176.x.
Rebhun U., 2014. Immigrant Acculturation and Transnationalism: Israelis in the United States and Europe Compared. Journal for the Scientific Study of Religion, vol. 53, iss. 3, pp. 613-635, DOI: $10.1111 /$ jssr.12135.

Rhodes D., 2016. The Dual Role a Buddhist Monk Played in the American South: The Balance between Heritage and Citizenship in the Refugee Community. Religions, vol. 50, iss. 7. DOI:10.3390/rel7050050.

\section{Information about the Author}

Elena V. Grunt, Doctor of Sciences (Philosophy), Professor, Department of Applied Sociology, Ural Federal University named after the First President of the Russian Federation B.N. Yeltsin, Mira St., 19, 620077 Yekaterinburg, Russian Federation, helengrunt2002@yandex.ru, https://orcid.org/0000-0002-2284-543X

\section{Информация об авторе}

Елена Викторовна Грунт, доктор философских наук, профессор, профессор кафедры прикладной социологии, Уральский Федеральный университет им. первого Президента РФ Б.Н. Ельцина, ул. Мира, 19, 620077 г. Екатеринбург, Российская Федерация, helengrunt2002@yandex.ru, https://orcid.org/0000-0002-2284-543X 